\title{
Characteristics of Medico-Legal Cases and Errors in Medico-Legal Reports at a Teaching Hospital in Saudi Arabia
}

\author{
Mohammed Madadin (D)' \\ Abdullah A Alqarzaie' \\ Rashed S Alzahrani' \\ Faisal F Alzahrani' \\ Saleh M Alqarzea' \\ Khalid M Alhajri ${ }^{1}$ \\ Mohammed A Al Jumaan (D) ${ }^{2}$ \\ 'College of Medicine, King Fahad \\ Hospital of the University, Imam \\ Abdulrahman Bin Faisal University, \\ Dammam, Saudi Arabia; ${ }^{2}$ Department of \\ Emergency Medicine, College of \\ Medicine, King Fahad Hospital of the \\ University, Imam Abdulrahman Bin Faisal \\ University, Dammam, Eastern Province, \\ Saudi Arabia
}

\begin{abstract}
Introduction: A medico-legal case (MLC) involves any injury or medical condition in which law enforcement agencies investigate and fix the responsibility regarding of an injury or medical condition. Incorrect or incomplete medico-legal reports (MLRs) may trigger a pause or delay in legal proceedings and patients' rights could be violated. The aim of this study is to describe the characteristics of MLCs and to identify errors in the MLRs.

Materials and Methods: This retrospective, descriptive study was conducted in a teaching hospital in the Eastern Province of Saudi Arabia. In total, 418 MLRs furnished during a 6-month period and reviewed for characteristics of MLCs and identification of errors.

Results: A total of 418 MLRs were included in the present study. Fights or physical assault and battery formed the major proportion of MLCs amounting to $83 \%$ of MLCs. Blunt injury was the dominant type of injury in most of the cases (81.8\%). In relation to errors in MLRs, no MLR in the present study were without errors.

Conclusion: Fights or physical assault and battery formed the major proportion of MLCs. Multiple errors were identified in the MLRs furnished by the physicians. Writing MLRs must follow standardized guidelines as it has a bearing on legal proceedings and patients' rights. We recommend training for physicians in writing MLRs in the interest of proper administration of justice.
\end{abstract}

Keywords: medico-legal case, injury, medico-legal report, Saudi Arabia

\section{Introduction}

A medico-legal case (MLC) applies to any case of injury or medical condition in which law enforcement agencies seek to investigate and fix the responsibility regarding the said injury or medical condition. ${ }^{1}$ From a physician's perspective, a MLC is a medical or clinical case with legal implications. In such cases presented directly to the hospital, after obtaining a detailed history and examination of the patient, the physician concludes the need for the law enforcement administration to investigate further. Besides, such cases could also be referred to the physician by the law enforcement administration for application of medical expertise and opinion to aid in the administration of justice. ${ }^{2}$

Several MLCs presented to the emergency medicine department include accidents, criminal or self-inflicted injuries such as fights or physical assault and battery, poisonings, road traffic accidents, burns, falls, bites, and others. ${ }^{1,3,4}$

MLCs are often encountered by physicians working in the emergency medicine department of hospitals. In an MLC, the hospital medical record pertaining to the
Correspondence: Mohammed Madadin Department of Pathology, College of Medicine, King Fahad Hospital of the University, Imam Abdulrahman Bin Faisal University, Dammam, 342II, Saudi Arabia Tel +966 I3 3333766

Fax +966 I3 3330333

Email Mmadadin@iau.edu.sa 
case and the medico-legal report (MLR) furnished by the physician are vital. An MLR is a report drafted by a physician for legal proceedings. It is considered to be the written evidence of the physician who has examined the case and documented the findings. In many countries like Saudi Arabia, an MLR is prepared when requested by authority. $^{3}$

Writing the MLR efficiently will provide a comprehensive understanding of how critical the injury is and its significance, helping the law enforcement agencies to further investigate and decide. Medico-legal documentation contains the holistic documentation of the clinical aspects of a case and information required by the courts. ${ }^{5}$ Documentation of injury may include the type, size, location, direction of injury, age of injury, and recovery time and direction of injury. ${ }^{5}$ Therefore, an MLR is critical since it provides significant written evidence of the medical expert to the courts. Incorrect or incomplete reports may trigger a pause or delay in legal proceedings, and victims' rights could be violated. ${ }^{2}$ The most common errors in MLR are poor identification of external traumatic lesion, failure to document cooperative, and consciousness status. ${ }^{2}$ Documentation of the type of injury and its description helps in inferring the causative weapon or agent. For instance, abrasions, contusions, and lacerations are caused by blunt force impact, whereas incised wounds are caused by sharp force impact. ${ }^{6}$

The aim of this study was twofold: (1) to describe the characteristics of MLCs and (2) to identify errors in the MLRs furnished by the physicians working in the emergency medicine department of a teaching hospital in Saudi Arabia.

\section{Materials and Methods Study Design}

Retrospective data collection, descriptive, noninterventional.

\section{Study Setting and Data Collection}

This study was conducted at XYZ (anonymized), an affiliate teaching hospital of XYX (anonymized), Saudi Arabia. MLCs are encountered by physicians working in the emergency medicine department of the hospital. Electronic medical records archived in the medical records department were scrutinized during the 2020 for cases tagged as MLCs with MLRs for a period of six months from 01January-2020 to 30-June-2020. During this period, 1051 cases were registered as MLCs with MLRs furnished. Of this pool, 418 MLRs were chosen randomly. MLRs were in the form of scanned digitally written documents stored within the electronic medical records system in the medical records department.

\section{Study Parameters}

Variables considered for studying the characteristics of MLCs included the following: demographic information of patients (age and sex), nature of injuries, and types of injuries documented on MLRs. Information pertaining to the time of admission of the patient, level of consciousness status of the patient, estimated recovery time, description of injuries, information of the physician certifying the MLR, and information of the law enforcement agency personnel receiving the MLR were reviewed to identify errors in MLRs.

\section{Statistical Analysis}

Data were entered to a Microsoft Excel worksheet and analysed using IBM Statistical Package for Social Sciences (SPSS), version 21.0. Variables were expressed as frequencies and percentages.

\section{Ethical Considerations}

The present study was conducted after obtaining approval from the Ethics Committee of XYZ (anonymized) (Reference number: IRB-UGS-2020-01-290). Personally identifiable data of the patients was not collected during data collection; thus, the data was handled anonymously. The data collected were secured in a password-protected device.

\section{Results}

A total of 418 MLRs issued from the emergency medicine department were analysed. Of the MLRs reviewed, 299 (71.5\%) were males and 119 (28.5\%) were females. The majority $(63.4 \%)$ were in the age group of 18-35 (Table 1).

Over two-third of the cases $(293,70.1 \%)$ were due to fights where the patient admitted was also actively involved in inflicting injury to another person or persons, followed by cases of physical assault and battery (54, $12.9 \%$ ) where the patient admitted had not inflicted any injury to another person or persons. Nearly one-tenth $(10 \%)$ of the cases were related to road traffic accidents where the patient was either a car occupant $(37,8.9 \%)$ or a pedestrian $(2,0.5 \%)$. In $5.7 \%$ (24) of the cases, the nature of injury was not documented (Table 2). 
Table I Demographic Information of Patients in Medico Legal Cases

\begin{tabular}{|l|l|}
\hline Variable & Percentage (N) \\
\hline Sex & \\
Male & $71.5 \%(299)$ \\
Female & $28.5 \%(119)$ \\
\hline Age & \\
$<18$ & $6.9 \%(29)$ \\
$18-35$ & $63.4 \%(265)$ \\
$36-60$ & $27.8 \%(116)$ \\
$>60$ & $1.9 \%(8)$ \\
\hline
\end{tabular}

Table 2 Characteristics of Medico Legal Cases

\begin{tabular}{|l|l|}
\hline Variable & Percentage (N) \\
\hline Nature of injury & \\
Fight $^{\mathrm{a}}$ & $70.1 \%(293)$ \\
Physical assault and battery $^{\mathrm{b}}$ & $12.9 \%(54)$ \\
Road traffic accident $^{\text {Missing data (not specified) }}$ & $9.3 \%(39)$ \\
Non-traffic accident & $5.7 \%(24)$ \\
Sexual abuse & $1.2 \%(5)$ \\
Self-injury/suicide attempt & $0.20 \%(1)$ \\
Intoxication & $0.20 \%(1)$ \\
\hline Dominant type of injury & $0.20 \%(1)$ \\
Blunt injury & \\
Fracture & \\
Sharp injury & $81.8 \%(342)$ \\
Missing data (not specified) & $9.8 \%(41)$ \\
Bite wound & $8.4 \%(35)$ \\
Burn wound & $5.7 \%(24)$ \\
Firearm injury & $2.4 \%(10)$ \\
\hline
\end{tabular}

Notes: a Patient actively involved in inflicting injury to another; ${ }^{\mathrm{b}}$ Patient not involved in inflicting injury to another; 'Includes lacerations and contusions.

Different types of injuries were present in cases with multiple injuries. Blunt injury was the dominant type of injury in most of the cases $(342,81.8 \%)$. The type of injury was not documented in $5.7 \%$ (24) of the cases (Table 2).

Table 3 summarizes the errors in MLRs. The time of admission of the patient was not documented in all the reports $(100 \%)$. The level of consciousness status of the patient and the estimated recovery time was not documented in $98.8 \%$ and $1.4 \%$ of the reports, respectively. Lack of documentation of the size of injury (98.1\%), incomplete description of the type of injury (41.9\%), lack of documentation of the time since injury (26.1\%), and not specifying the location of injury (5.5\%) were the errors related
Table 3 Errors in Medico Legal Reports

\begin{tabular}{|l|l|}
\hline Types of Error & $\begin{array}{l}\text { Percentage } \\
(\mathbf{N})\end{array}$ \\
\hline Time of admission was not written & $100 \%(418)$ \\
Designation of the physician was not written & $99.5 \%(416)$ \\
Level of consciousness status was not written & $98.8 \%(413)$ \\
Size of injury was not written & $98.1 \%(410)$ \\
Life threatening status was missing & $77.3 \%(323)$ \\
Description of the type of injury was not & $41.9 \%(175)$ \\
complete & \\
Age of injury was not written & $26.1 \%(109)$ \\
Non specified injury & $5.7 \%(24)$ \\
Location of injury was not written & $5.5 \%(23)$ \\
Estimated recovery time was missing & $1.4 \%(6)$ \\
Data of the receiving person was not written & \\
\hline
\end{tabular}

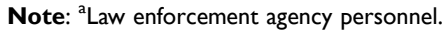

to description of injuries observed in MLRs. The designation of the physician certifying the report was not documented in almost all the cases. However, information pertaining to the law enforcement agency personnel receiving the MLR was not documented only in less than $1 \%$ of the reports.

\section{Discussion}

In the present study conducted in Saudi Arabia, MLRs were reviewed to highlight the characteristics of MLCs and errors in MLRs furnished by the physicians working in the emergency medicine department of a teaching hospital. Here, more than two-thirds of the MLCs involved males as the patients, which is consistent with other studies conducted in India, Turkey and Spain. ${ }^{1-3}$ This could be attributed to males engaging in behavior that exposes them more to the risk of injury. The age groups $18-35$ and 36-60 formed most of the patients, amounting totally to $91.2 \%$ of the MLCs. This demographic variable of age appears consistent with previous reports across different countries. ${ }^{1-3}$ These age groups are economically active and more often involved in outdoor activities, thus being more prone to injuries.

Fights or physical assault and battery formed the major proportion of MLCs, amounting to $83 \%$ of cases in total in the present study. This incidence is much higher than that reported in studies conducted in India and Turkey, where $30.5 \%$ of MLCs victims of violent crime and $27.2 \%$ of MLCs involved assaults, respectively. ${ }^{1,2}$ A cross-sectional study in India reported assault by blunt and hard objects to be the most common MLC. ${ }^{1}$ Another retrospective study 
in India reported that the most common MLC presented to the emergency medicine department was an assault. ${ }^{7}$ Studies conducted in Turkey and Spain reported traffic accidents to be the most common type of MLC presented to the emergency medicine department. ${ }^{2,3}$

Internationally, a wide range of studies have reported a significant proportion of MLCs to be road traffic accidents. ${ }^{1,2,8,9}$ However, in the present study, road traffic accidents accounted for less than $10 \%$ of the MLCs examined in the emergency medicine department. This is possibly because not all road traffic accidents are reported as MLCs in Saudi Arabia, so this does not mean that road traffic accidents are less in Saudi Arabia. A study from Sri Lanka explored occupational related injuries as MLCs for compensation purposes. ${ }^{10}$ However, this study only reviewed cases that encountered in emergency department without further explanation whether work related or not.

Blunt injury was the dominant type of injury observed in $81.8 \%$ of the cases in the present study. A similar finding was observed in a study conducted in Pakistan, where $65.85 \%$ of patients sustained injuries due to blunt weapons. ${ }^{11}$ Sharp injury was the dominant injury in less than $10 \%$ of the present cohort of cases. This appears consistent with the findings reported in a Pakistani study in which $6.09 \%$ of patients sustained injuries due to sharpedged weapons. ${ }^{11}$ In a study conducted in India, Brahmankar and Sharma ${ }^{1}$ reported that $95 \%$ and $5 \%$ of the assaults were carried out using blunt weapons and sharp-edged weapons, respectively. Less than $1 \%$ of the cases were due to firearm injury in the present study, which is consistent with the incidence of firearm injury reported in a Turkish study in which $1.3 \%$ of cases were due to firearm injury. ${ }^{2}$

With reference to the errors in MLRs, no MLR in the present study were without errors. Multiple errors were identified in the present study. Lack of documentation of the time of admission of the patient, the level of consciousness status of the patient, and the designation of the physician certifying the MLR were the top three errors encountered in the present study in more than $98.5 \%$ of the cases. In contrast, a Turkish study by Aktas and colleagues reported that the level of consciousness status of the patient was not documented in only $1.8 \%$ of the cases. ${ }^{2}$ However, another Turkish study by Turla and colleagues reported a lack of documentation of the level of consciousness status of the patient in $58.7 \%$ of the cases. The Turkish study by Turla et al reported that the name of the physician who drafted the MLR was not documented in $8 \%$ of the cases. ${ }^{12}$ In the present study, information pertaining to the law enforcement agency personnel receiving the MLR was not documented only in less than $1 \%$ of the reports, contrary to that reported in the Turkish study by Turla et al in which this information was not documented in all the reports. ${ }^{12}$

In the present study, in relation to the documentation of injuries, the most common error was the lack of documentation of the size of the injury in $98.1 \%$ of the cases, followed by incomplete description of the type of injury and lack of documentation of the age of injury in $41.9 \%$ and $26.1 \%$ of cases, respectively. Studies conducted in Turkey by Aktas et $\mathrm{al}^{2}$ and Turla et $\mathrm{al}^{12}$ reported poor identification of external traumatic lesion in $62.4 \%$ and $30.5 \%$ cases, respectively.

Standard guidelines and proper practice principles should be followed while writing the MLR. In addition to patient care responsibility, the physician may be obliged to write the MLR in a precise, standardized way and report findings of MLCs to the concerned legal authorities. Besides, the physician must be unbiased while drafting the MLR. ${ }^{13}$ However, significant numbers of physicians do not understand their responsibility in writing MLRs, and therefore, there is a need to train physicians in writing MLRs. ${ }^{14}$ In a study conducted in Egypt, $67.1 \%$ of the physicians reported difficulty in writing MLRs. ${ }^{15}$ A well-designed MLR pertaining to trauma should incorporate detailed information such as demographic parameters of the patient including personally identifiable information, personal details (name, designation, institutional affiliation, signature) of the physician drafting the MLR, date and time of admission and examination, history of the incident, consent of the patient, general condition of the patient on arrival, detailed account of injuries including description of the type of injury, dimensions of injury, location of injury, illustrative presentation of injuries, and opinion on the age of injury, severity of injury (simple or grievous), and type of weapon used. ${ }^{8}$

\section{Limitations}

The current study has potential limitations. This is a single center study that may cannot be generalized. Further studies should include multiple centers in the country. In addition, all reports were in Arabic language and translated to English. Moreover, the study period is six months only, which might does not represent the full nature of 
medico-legal cases encountered in the after mentioned hospital.

\section{Conclusion}

This study described the characteristics of MLCs and identified the errors in the MLRs furnished by the physicians working in the emergency medicine department of a teaching hospital in Saudi Arabia.

Males and individuals in the age group of 18-35 formed the major proportion of the cohort in the present study that reviewed MLRs furnished by physicians working in the emergency medicine department of a teaching hospital in Saudi Arabia. Fights or physical assault and battery formed the major proportion of MLCs. Blunt injury was the dominant type of injury in most of the cases. Multiple errors were identified in the MLRs furnished by the physicians. The findings of current study are similar of what presented in the literature. ${ }^{16}$ With reference to errors in MLRs, the time of admission of the patient, the level of consciousness status of the patient, and the designation of the physician certifying the MLR were not documented in almost all the cases. In relation to the documentation of injuries, the most common error was the lack of documentation of the size of the injury, followed by incomplete description of the type of injury and lack of documentation of the age of injury. Writing MLRs must follow standardized guidelines as it has a bearing on legal proceedings and patients' rights. We recommend training for physicians working in the emergency medicine department in writing MLRs in the interest of proper administration of justice.

\section{Ethical Approval}

This study was approved by the Institutional Review Board (IRB) of Imam Abdulrahman Bin Faisal University, Dammam, Saudi Arabia. The authors confirm that this study was conducted in accordance with the Declaration of Helsinki.

\section{Author Contributions}

$\mathrm{MM}$ and $\mathrm{MJ}$ conceived and designed the study; $\mathrm{AA}$ acquired the data and is the guarantor. AA, RA, FA, SA and KA conducted a literature survey and collected data. All authors contributed to data analysis, drafting or revising the article, have agreed on the journal to which the article will be submitted, gave final approval of the version to be published, and agree to be accountable for all aspects of the work.

\section{Funding}

There is no funding to report.

\section{Disclosure}

The authors report no conflicts of interest in this work.

\section{References}

1. Brahmankar TR, Sharma SK. A record-based study of frequency and pattern of medico-legal cases reported at a tertiary care hospital in Miraj. Int J Community Med Public Health. 2017;4:1348-1352. doi:10.18203/2394-6040.ijcmph20171374

2. Aktas N, Gulacti U, Lok U, Aydin I, Borta T, Celik M. Characteristics of traumatic forensic cases admitted to emergency medicine and errors in the forensic report writing. Bull Emerg Trauma. 2018;6(1):64-70. doi:10.29252/beat-060110

3. Linares-Gonzalez L, Rodriguez JS, Beltran-Aroca CM, Girela-Lopez E. Quality control of injury reports issued by primary health care and emergency medical services in the province of Cordoba. Rev Esp Med Legal. 2019;45(1):12-17.

4. Siddappa SC, Datta A. A study pattern of medico-legal cases treated at a tertiary care hospital in central Karnataka. Indian J Forensic Community Med. 2015;2(4):193-197. doi:10.5958/23946776.2015.00002.8

5. Kotze JM, Brits H, Botes BA. Medico-legal documentation: South African police service forms, department of justice forms and patient information. S Afr Fam Pract. 2014;56:16-22.

6. Acharya J, Shrestha R. Documenting Injuries for Medico-Legal Use: A “Must-Know" to Doctors. Meleson Newsletter; 2017:6-9.

7. Haridas SV, Pawale DA. A retrospective study of pattern of clinical medico-legal cases registered at tertiary health care centre in Kolhapur district. J Forensic Med Sci Law. 2014;23:1-5.

8. Chaudhary B, Shukla PK, Bastia BK. Role of clinical forensic medicine unit in quality and standardization of medico-legal reports. J Forensic Leg Med. 2020;74:102007. doi:10.1016/j. jflm.2020.102007

9. Malik R, Atif I, Rashid F, Abbas M. An analysis of 3105 medico legal cases at tertiary care hospital, Rawalpindi. Pak J Med Sci. 2017;33(4):926-930. doi:10.12669/pjms.334.11696

10. Kitulwatte IDG, Edirisinghe PAS. An analysis of medicolegal reporting in workman injuries referred for medicolegal examination in a tertiary care hospital of Sri Lanks. Indian J Occup Environ Med. 2020;24(2):55-59. doi:10.4103/ijoem.IJOEM_81_20

11. Jadoon OK, Shireen F, Seema N, et al. Types of medico-legal cases reported at the casualty department of Ayub Teaching Hospital Abbottabad. J Ayub Med Coll Abbottabad. 2020;32(1):51-53.

12. Turla A, Aydin B, Sataloğlu N. [Mistakes and omissions in judicial reports prepared in emergency services]. Ulus Travma Acil Cerrahi Derg. 2009;15(2):180-184. Turkish.

13. Akbaba M, Das V, Asildag MK, et al. Are the judicial reports prepared in emergency services consistent with those prepared in forensic medicine department of a university hospital? Eurasian J Emerg Med. 2019;18(2):79-85. doi:10.4274/eajem. galenos.2018.93723

14. Zaki MK, Bayoumi KA, Rawas MI, et al. Measuring the awareness of emergency medicine physicians toward the management of medicolegal cases in Jeddah, Saudi Arabia. Saudi J Forensic Med Sci. 2018;1(3):61-67. doi:10.4103/sjfms.sjfms_13_18

15. Mokhtar M, Azab SMS, Hassan S, Ez-Elarab HS. Study of handling of medico-legal cases in governmental hospitals in Cairo. J Forensic Leg Med. 2018;60:15-24. doi:10.1016/j.jflm.2018.09.001

16. Hassan Q, Bashir MZ, Shah MM. Physical trauma-a leading cause of medico legal cases at DHQ Hospital Abbottabad. J Ayub Med Coll Abbottabad. 2010;22(2):156-159. 


\section{Publish your work in this journal}

The Open Access Emergency Medicine is an international, peerreviewed, open access journal publishing original research, reports, editorials, reviews and commentaries on all aspects of emergency medicine. The manuscript management system is completely online

Submit your manuscript here: https://www.dovepress.com/open-access-emergency-medicine-journa and includes a very quick and fair peer-review system, which is all easy to use. Visit http://www.dovepress.com/testimonials.php to read real quotes from published authors. 